\title{
Edible Medicines: An Ethnopharmacology of Food
}

Nina Etkin. 2006. University of Arizona Press, Tucson. Pp. 304. \$24.95 (paper). ISBN 9780816527489.

\author{
Reviewed by Laura Barbas-Rhoden ${ }^{1}$ \\ Reviewer Address: ${ }^{1}$ Department of Foreign Languages, Wofford College 29303
}

Received: December $6^{\text {th }} 2009$

Volume 1:14-15

Published: August $4^{\text {th }} 2010$

(C) 2010 Society of Ethnobiology

What are the health implications of cuisines in different cultures? How have different human communities managed the physiologic effects of foods, many of which have non-nutritive constituents? Edible Medicines is a wide-ranging study that investigates such questions from an anthropological and biocultural perspective. It is the third book on an ethnobiological topic by the late Nina L. Etkin, the renowned University of Hawai'i anthropologist who died in January 2009. Etkin served as past president of the International Society for Ethnopharmacology and was named one of two recipients of the 2009 Distinguished Economic Botanist Award by the Society for Economic Botany (SEB). Her influence extends through dozens of graduate students whom she mentored, as well as a lengthy list of academic publications. The volume reviewed here is highly indicative of the interdisciplinary scope of her scholarship.

One of the single most important accomplishments of Edible Medicines is its recovery of a history in which the lines between foods and medicines have been either blurry or nonexistent. Informed by both an anthropological and historical perspective, Etkin's scholarship implicitly and explicitly raises provocative questions regarding the atomization of scholarship in the West. As the author points out, this atomization of scholarship has led to the study of food in particular categories of study like nutrition, biochemistry, agriculture, and medicine, with little attention paid, until recently, to the "pharmacologic potential of diet" (3). Etkin's book proposes an anthropological methodology by which to consider the pharmacologic potential of foods selected by cultures around the world for specific uses. Using concrete cultural examples, Etkin discusses the uses of foods by diverse peoples of the world, and she brings an anthropological discussion into dialogue with plant and nutritional science. The result is a study useful for scholars in ethnobiology, anthropology, food science, and nutrition, but one that also has appeal for nonspecialists and undergraduate students.

Etkin's introduction covers the basic scientific principles of plant metabolism, defense, and reproduction, and relates this to subsistence strategies of humans. The introduction also sketches a brief overview of transformations in subsistence in human history, from foraging to pastoralism and horticulture and agriculture. Finally, the introduction contextualizes food use in cultural context and addresses the "social organization of eating" (42).

Chapter Two, "Food in the History of Biomedicine," considers the place of food in Western biomedicine from ancient times to present and offers specific examples of transformations of thought in particular cultures. Though the focus is on biomedicine in the West, Etkin also documents the ways in which Arabic and other medical philosophies influenced thoughts about sickness and health from the eighth to the eleventh centuries in Europe (51). The chapter concludes by posing the question of whether or not medicine in the West has entered a new phase in which "preventive and curative modalities ... now approximate one another" (81).

With the background information sketched clearly and succinctly, Etkin follows the two opening chapters with more specific categories of study. Chapters consider spices; fermented foods and beverages; social plants (foods like tea and masticatories like kola and coca); animal foods with medicinal qualities; and food in contemporary complementary and alternative medicine. These chapters are thorough without attempting to be tediously exhaustive, and they broadly contextualize food use in economic and cultural history of specific practices related to food as medicine.

All chapters are well written and readable, though some tell stories that will be more compelling for some readers than others, depending on their particular background or field of interest. For example, the 
chapter on fermentation gives a basic definition of the process of fermentation and identifies the biological substrates of fermentation in the Old World and New World. After drawing attention to the "ubiquity and sophistical of techniques" (110) involved in food fermentation, Etkin points out the nutritional and therapeutic benefits of fermented foods over their nonfermented state. She does not limit herself to only a discussion of the science of allergens, glycosides, and lectins, but rather also takes into consideration palatability and particular cultural applications in the cultures of Nigeria.

Throughout the book, Etkin draws from her own ethnographic work among the Hausa of Nigeria. This provides a sustained cultural example to undergird the categories of analysis she proposes. The book is a welcome addition to the scant selection of volumes on the ethnopharmacological implication of foods and will be of use to scholars and students in a variety of disciplines and settings. 